\title{
The Changing Face of Nuclear Cardiology: Guiding Cardiovascular Care Toward Molecular Medicine
}

\author{
Rudolf A. Werner ${ }^{1}$, James T. Thackeray ${ }^{1}$, Johanna Diekmann ${ }^{1}$, Desiree Weiberg ${ }^{1}$, Johann Bauersachs ${ }^{2}$, \\ and Frank M. Bengel ${ }^{1}$ \\ ${ }^{1}$ Department of Nuclear Medicine, Hannover Medical School, Hannover, Germany; and ${ }^{2}$ Department of Cardiology and Angiology, \\ Hannover Medical School, Hannover, Germany
}

\begin{abstract}
Radionuclide imaging of myocardial perfusion, function, and viability has been established for decades and remains a robust, evidencebased and broadly available means for clinical workup and therapeutic guidance in ischemic heart disease. Yet, powerful alternative modalities have emerged for this purpose, and their growth has resulted in increasing competition. But the potential of the tracer principle goes beyond the assessment of physiology and function, toward the interrogation of biology and molecular pathways. This is a unique selling point of radionuclide imaging, which has been underrecognized in cardiovascular medicine until recently. Now, molecular imaging methods for the detection of myocardial infiltration, device infection, and cardiovascular inflammation are successfully gaining clinical acceptance. This is further strengthened by the symbiotic quest of cardiac imaging and therapy for an increasing implementation of molecule-targeted procedures, in which specific therapeutic interventions require specific diagnostic guidance toward the most suitable candidates. This review will summarize the current advent of clinical cardiovascular molecular imaging and highlight its transformative contribution to the evolution of cardiovascular therapy beyond mechanical interventions and broad blockbuster medication, toward a future of novel, individualized molecule-targeted and molecular imaging-guided therapies.
\end{abstract}

Key Words: nuclear cardiology; molecular imaging; inflammation; cardiovascular infection; infiltrative cardiomyopathy

J Nucl Med 2020; 61:951-961

DOI: 10.2967/jnumed.119.240440

$\mathbf{T}$ racing its roots to the early 1970 s, radionuclide imaging of the heart has been well established as a centerpiece of clinical practice in nuclear medicine (1). Today, nuclear cardiology robustly serves as a gatekeeper to the cardiac catheterization laboratory, by determining the functional and prognostic relevance of coronary artery disease (2). However, in recent years, alternative imaging modalities have emerged for this purpose, backed by evidence from randomized clinical trials-for example, invasive fractional flow reserve as a reference standard for functional guidance of percutaneous coronary intervention (3). Cardiac MRI is as

Received Feb. 10, 2020; revision accepted Mar. 25, 2020.

For correspondence or reprints contact: Frank M. Bengel, Klinik für Nuklearmedizin, Medizinische Hochschule Hannover (MHH), Carl-NeubergStrasse 1, D-30625 Hannover, Germany.

E-mail: bengel.frank@mh-hannover.de

Published online Apr. 17, 2020.

COPYRIGHT (C) 2020 by the Society of Nuclear Medicine and Molecular Imaging. effective as SPECT in reducing the number of invasive coronary angiography procedures (4), and its use as a gatekeeper leads to reduced rates of coronary revascularization compared with assessments with fractional flow reserve (5). Last, the use of coronary CT angiography in patients with stable chest pain lowers the rate of nonfatal myocardial infarction (6), leading to equal outcome when compared with functional imaging, including echocardiography and SPECT (7). This ongoing competition by cardiac MRI, coronary CT angiography, and fractional flow reserve for diagnosis and guidance of intervention in stable coronary artery disease has increased the evolutionary pressure on nuclear cardiology. The resulting refinement of radionuclide imaging methodology has opened avenues for further advances in the field and supports the changing face of nuclear cardiology, in which increasingly specific molecule-targeted imaging techniques find growing clinical applications.

\section{STATE-OF-THE-ART METHODOLOGY FOR CARDIOVASCULAR RADIONUCLIDE IMAGING}

Clinical cardiac SPECT is characterized by several methodologic advances. First, there is a strong trend toward shorter acquisition times and reduced radiation exposure. This can be realized using standard dual-head SPECT systems, such as by using innovative focal collimators for cardiocentric acquisitions, along with advanced iterative reconstruction algorithms (8). Alternatively, new solid-state detector technology, such as cadmium-zinc-telluride detectors, has been introduced for dedicated cardiac SPECT systems. Acquisition times may be substantially reduced, or radiation dose may be lowered while still achieving image quality superior to conventional SPECT (8).

Beyond SPECT, the use of PET in cardiology is expanding worldwide, supported by its increasing availability due to the success in nuclear oncology (9). Cardiac PET methodology is more accurate than SPECT, and it yields robust absolute quantification (10). Recent developments in ${ }^{18} \mathrm{~F}$-labeled perfusion radiotracers will further increase clinical penetration because of relief from on-site production (11).

Last, nuclear cardiology has also benefited from the widespread acceptance of hybrid imaging technology. Combination of nuclear imaging with CT allows assessment of functional and morphologic abnormalities in a single setting, such as by integrating perfusion assessment with coronary calcium scoring (12). The recent introduction of hybrid PET/MRI adds another dimension, wherein cardiac MRI may provide anatomic, functional, and tissue information while PET adds simultaneous metabolic or molecular information (13). Diagnostic confidence may be also improved by solid-state 
TABLE 1

Key Technical Advances in Nuclear Cardiology

\begin{tabular}{|c|c|}
\hline Innovation & Result \\
\hline Clinical cardiac PET & Improved speed and accuracy, absolute quantification, list-mode acquisition \\
\hline Cardiocentric SPECT collimators & Increased count sensitivity, improved speed, lower dose \\
\hline Solid-state detector SPECT & $\begin{array}{l}\text { Increased count sensitivity, improved speed, lower dose, list-mode acquisition, } \\
\text { multiisotope acquisition }\end{array}$ \\
\hline Iterative reconstruction algorithms & Resolution improvement, noise reduction \\
\hline List-mode acquisition & $\begin{array}{l}\text { Integration of ECG and respiratory gating, motion correction, dynamic imaging } \\
\text { sequences for kinetic analysis, simultaneous multiisotope SPECT }\end{array}$ \\
\hline Motion correction & Improved resolution for analysis of small target regions \\
\hline Tracer kinetic analysis & Absolute quantification of physiologic and biologic processes (blood flow, metabolic rates) \\
\hline Hybrid SPECT/CT, PET/CT & $\begin{array}{l}\text { Attenuation correction, integration with calcium score and CT-based coronary } \\
\text { angiography, morphologic coregistration }\end{array}$ \\
\hline Integrated PET/MRI & $\begin{array}{l}\text { Integration with morphology, function, and tissue characteristics; simultaneous } \\
\text { multiparametric imaging }\end{array}$ \\
\hline SiPM DPC PET/CT & Improved resolution, improved speed, lower dose \\
\hline \multicolumn{2}{|c|}{$\overline{E C G}=$ electrocardiography; SiPM DPC = solid-state silicon photomultiplier digital photon counting. } \\
\hline
\end{tabular}

silicon photomultiplier digital photon counting PET/CT systems (14). Table 1 summarizes the technical advances of radionuclide cardiac imaging methods.

\section{RADIOTRACERS FOR CARDIAC IMAGING: FROM FUNCTIONAL TO MOLECULAR IMAGING}

In nuclear cardiology, the major focus in tracer development has traditionally been on identifying the best-suited agent for myocardial perfusion assessment, based on physiologic parameters such as first-pass extraction fraction, proportionality to flow, and tissue retention. These factors remain critical as the field progresses toward absolute flow quantification $(15,16)$. In combination with electrocardiographic gating, function can be better interpreted to guide revascularization (17). Perfusion imaging technically targets physiology and hence is not a molecular imaging technique in its basic sense.

True molecule-targeted imaging nevertheless has a longstanding track record in cardiovascular medicine. Insights into myocardial

\section{NOTEWORTHY}

- Nuclear cardiology currently evolves from assessing physiologic function and perfusion toward an interrogation of biology and molecular pathways.

- Molecular radionuclide-based imaging for the 3 "I's" (infection, infiltration, and inflammation) is successfully gaining clinical acceptance.

- These considerations are further fueled by the symbiotic quest of molecular cardiac imaging and therapy, ultimately leading to systems-based, image-guided, targeted therapy in cardiovascular medicine.

- Future opportunities in the field include assessment of imaging-guided drug development and systems-based imaging of organ crosstalk. metabolism are obtained by ${ }^{18} \mathrm{~F}$-FDG and other radiolabeled substrates, and the modulation of substrate metabolism by ischemia has long been used for PET-based assessment of myocardial viability (18). The spectrum of available molecule-targeted radiopharmaceuticals has expanded, stimulated by advances in other imaging fields. Such pathways include inflammation, fibrosis, and other extracellular matrix processes; angiogenesis; and cell death (Table 2) and have been extensively reviewed elsewhere $(19,20)$.

\section{FROM MECHANICAL TO MOLECULAR MEDICINE: THE EFFECT OF AVAILABLE THERAPY OPTIONS ON THE EVOLUTION OF CARDIOVASCULAR MOLECULAR IMAGING}

Despite advances in imaging technology and the increasing spectrum of radiopharmaceuticals, until recently molecular imaging in cardiovascular medicine did not reach a level of clinical acceptance similar to that in oncology or neurology. This lack of acceptance is best explained by the fact that targeted molecular therapies in cardiology have also lagged behind those in other fields, and molecular imaging works best in combination with molecular therapies. Traditionally, cardiovascular medicine has been dominated by mechanical interventions. The indication for coronary intervention, valvular intervention, pacemakers, implantable cardioverter-defibrillators, or other devices is effectively established by morphologic or functional imaging, without a clear need for novel molecule-targeted imaging.

The other main pillar of cardiovascular therapy is medical therapy with broadly applicable blockbuster drugs such as angiotensin-converting enzyme inhibitors, $\beta$-adrenergic receptor blockers, diuretics, antiplatelet agents, and lipid-lowering agents. Because such drugs show broad benefits and are affordable, their use even for general prevention in a combined poly-pill is under discussion for underserved populations (21). Molecular imaging may identify the target of these drugs directly, such as by visualizing angiotensin-converting enzyme (22) or $\beta$-adrenergic receptors (23). But given the low cost of the drugs and their broad applicability, image 
TABLE 2

Key Radiopharmaceuticals and Target Mechanisms in Clinical Nuclear Cardiology

\begin{tabular}{|c|c|}
\hline Tracer & Target mechanism \\
\hline \multicolumn{2}{|l|}{ SPECT } \\
\hline 99mTc-sestamibi, 99mTc-tetrofosmin, ${ }^{201} \mathrm{TI}$ & Myocardial perfusion \\
\hline 99mTc-PYP, 99mTc-DPD, 99mTc-HMDP & Cardiac amyloidosis \\
\hline 99mTc-HMPAO- or ${ }^{111}$ In-labeled WBC & Inflammation \\
\hline 123I-metaiodobenzylguanidine & Myocardial sympathetic innervation \\
\hline 123I-BMIPP & Fatty acid uptake \\
\hline 99mTc-annexin V & Apoptotic cell death \\
\hline 99mTc-RGD imaging peptide & $a_{v} \beta_{3}$ integrin expression \\
\hline \multicolumn{2}{|l|}{ PET } \\
\hline${ }^{15} \mathrm{O}$-water, ${ }^{13} \mathrm{~N}$-ammonia, ${ }^{82} \mathrm{Rb},{ }^{18} \mathrm{~F}$-flurpiridaz* & Myocardial perfusion, absolute myocardial blood flow \\
\hline${ }^{11} \mathrm{C}$-deoxyglucose & Glucose utilization (viability), inflammation \\
\hline${ }^{18}$ F-sodium fluoride & Microcalcification (atherosclerotic plaque) \\
\hline${ }^{11} \mathrm{C}-\mathrm{PiB},{ }^{18} \mathrm{~F}$-florbetaben, ${ }^{18} \mathrm{~F}$-florbetapir & Cardiac and extracardiac amyloidosis \\
\hline${ }^{11} \mathrm{C}$-acetate & Oxidative metabolism, cardiac efficiency \\
\hline${ }^{11} \mathrm{C}$-palmitate, ${ }^{11} \mathrm{C}$-lactate, ${ }^{11} \mathrm{C}$-glucose, ${ }^{18} \mathrm{~F}-\mathrm{FTHA}$ & Various aspects of myocardial substrate metabolism \\
\hline${ }^{11} \mathrm{C}-\mathrm{mHED},{ }^{11} \mathrm{C}$-epinephrine, ${ }^{18} \mathrm{~F}$-LMI1195* & Myocardial sympathetic innervation \\
\hline${ }^{11} \mathrm{C}-\mathrm{CGP} 12177,{ }^{11} \mathrm{C}-\mathrm{MQNB},{ }^{11} \mathrm{C}-\mathrm{KR} 31173$ & $\begin{array}{l}\text { Receptors of neurohumoral system ( } \beta \text {-adrenergic, } \\
\text { muscarinic, angiotensin) }\end{array}$ \\
\hline${ }^{68} \mathrm{Ga}$-pentixafor, ${ }^{68} \mathrm{Ga}-$ dotatate, ${ }^{11} \mathrm{C}-\mathrm{PK} 11195$ & $\begin{array}{l}\text { Receptors involved in inflammatory pathways (CXCR4, } \\
\text { somatostatin type } 2, \mathrm{TSPO})\end{array}$ \\
\hline${ }^{18} \mathrm{~F}$-fluciclatide, ${ }^{68} \mathrm{Ga}-\mathrm{FAPI}$ & $\begin{array}{l}\text { Targets involved in extracellular matrix reorganization } \\
\left(a_{v} \beta_{3} \text { integrin, myofibroblast) }\right.\end{array}$ \\
\hline
\end{tabular}

${ }^{* 18} \mathrm{~F}$-flurpiridaz and ${ }^{18} \mathrm{~F}-\mathrm{LM}$ 11195: preapproval evaluation in clinical trials.

PYP = pyrophosphate; DPD = diphosphonopropane dicarboxylic acid; HMDP = hydroxymethylene diphosphonate; HMPAO = hexamethyl-propylene-amine-oxime; WBC $=$ white blood cells; BMIPP $=\beta$-methyl-iodophenyl-pentadecanoic acid; RGD $=$ arginylglycyl-aspartic acid; PiB = Pittsburgh compound B; FTHA = fluorothioheptadecanoic acid; mHED = meta-hydroxyephedrine; ${ }^{18} \mathrm{~F}-\mathrm{LMI} 1195=$ $\mathrm{N}$-[3-bromo-4-(3- ${ }^{18} \mathrm{~F}$-fluoro-propoxy)-benzyl]-guanidine; MQNB = methyl-quinuclidinyl benzilate; CXCR4 = CXC-motif chemokine receptor type

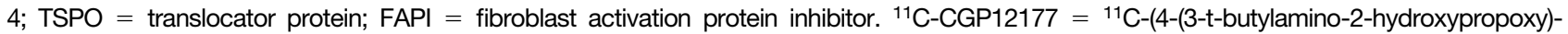
benzimidazol-1); ${ }^{11} \mathrm{C}-\mathrm{MQNB}={ }^{11} \mathrm{C}$-labeled methiodide quinuclidinyl benzilate; ${ }^{11} \mathrm{C}-\mathrm{KR} 31173={ }^{11} \mathrm{C}$-labeled 2 -Butyl-5-methoxymethyl-6-(1-oxopyridin-2-yl)-3-[[2-(1H-tetrazol-5-yl)biphenyl-4-yl] methyl]-3H-imidazo[4,5-b]pyridine; ${ }^{11} \mathrm{C}-\mathrm{PK} 11195=\left[{ }^{11} \mathrm{C}\right]-(\mathrm{R})-(2-\mathrm{chlorophenyl})-$ $N$-methyl- $N$-(1-methylpropyl)-3-isoquinoline-carboxamide PK11195.

guidance may be ineffective and a clinical role for molecular imaging is unlikely.

As an important development, advanced targeted drugs based on antibodies, small molecules, RNA products, or engineered cells are increasingly introduced into the cardiovascular field, such as for treating inflammatory conditions or interstitial disease. Their specificity will prevent the use of these drugs in broad populations, emphasizing the need for identifying homogeneous patient subsets that benefit most because their underlying disease is driven by a specific mechanism targeted by the respective drug (24). For this purpose, highly specific biomarkers are sought, and molecular imaging-derived biomarkers may have their strongest role (Fig. 1).

\section{THE SYNERGY OF TARGETED MOLECULAR IMAGING AND THERAPY: LESSONS LEARNED FROM OTHER AREAS OF MEDICINE}

The biomarker reference standard in molecular medicine is an in-depth analysis of tissue obtained from the target region. This, however, requires invasive biopsies that are often difficult to obtain, may suffer from sampling errors, and cannot easily be used for serial follow-up (25). Thus, liquid biopsies have recently been introduced as an alternative; these focus on disease components that can be accessed through analysis of the patient's blood but neglect intrinsic tumor heterogeneity (25). Imaging biomarkers, on the other hand, do not suffer from the potential risk of sampling error, are noninvasive, provide information about inter- and intraorgan heterogeneity, and allow for noninvasive whole-body read-outs and serial examinations (9). A molecule-targeted radiopharmaceutical assay provides tissue-specific information about the presence or absence of its respective target mechanism and could effectively guide therapy as a virtual biopsy.

In oncology, early evaluation of metabolic response to specific antitumor therapies is conducted with PET in a variety of entities (26). Furthermore, the theranostic principle for neuroendocrine tumors and prostate cancer is rapidly expanding (9).

The field of neurology has also been actively pursuing imaging biomarker-guided, targeted therapy concepts, mainly by providing important insights into disease processes followed by novel 


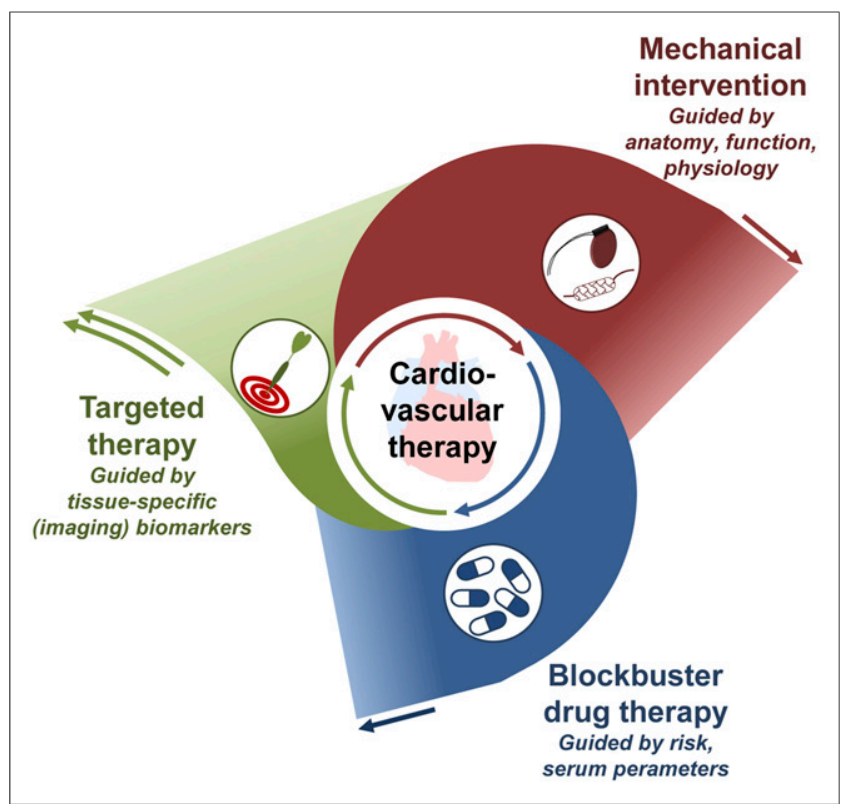

FIGURE 1. Growing role of molecule-targeted therapy in cardiovascular medicine. Targeted therapy is increasingly implemented to support and supplant broad blockbuster drug therapy and mechanical intervention, requiring specific guidance to the right patient at the right timeguidance that may be obtained by molecular imaging.

therapeutic targets. In Parkinson disease, for example, there is a longstanding track record for imaging of the dopaminergic system; such imaging not only may identify disease progression but also may determine the effectiveness of drug therapy (27). In Alzheimer disease, specific tracers targeting pathogenic substrates such as $\beta$-amyloid, tau protein, or neuroinflammation have been developed and are increasingly used for guiding and monitoring disease-modifying treatments, which in turn are expected to require improved biomarker guidance for success (28).

Taken together, progress in imaging technology and in radiopharmaceutical development, paralleled by an increased implementation of molecule-targeted therapies in cardiology and supported by proof of feasibility and the success of image-guided molecular therapy in other fields, provides the foundation for the emerging clinical penetration of cardiovascular molecular imaging (Fig. 2).

\section{THE THREE "I'S" (INFECTION, INFILTRATION, AND INFLAMMATION) AT THE VANGUARD OF CLINICAL CARDIOVASCULAR MOLECULAR IMAGING}

Cardiovascular device infection, infiltrative cardiomyopathies, and inflammatory conditions of the myocardium and vessel wall are areas that have an increasing clinical need for specific diagnosis and for guidance regarding specific therapy. In these areas, molecular radionuclide-based imaging has been growing rapidly, penetrating the clinical arena.

\section{Infection of Devices}

Because of their preeminent survival benefit, implants have seen exceptional success in cardiovascular medicine. Because intracorporeal artificial material supports adherence and growth of bacteria, device recipients are at increased risk of infections associated with substantial morbidity and mortality. Accurate diagnostic tools are needed for early identification of the severity, extent, and location of infection and for guidance of therapeutic options, which may include antibiotic drug therapy, surgical revision, or device extraction (29). Conventional echocardiography as the first-line test is often limited by device-related artifacts. Because of the potential that electromagnetic fields will interfere with the proper function of cardiac devices, and because of artifacts stemming from the implant material in devices that are safe to operate in a magnetic field, MRI is not an option and CT identifies only morphologic disease aspects (29). Moleculetargeted imaging techniques do not have these limitations. Accordingly, current guidelines propose ${ }^{18} \mathrm{~F}-\mathrm{FDG} \mathrm{PET} / \mathrm{CT}$ or white blood cell SPECT/CT in patients with suspected prosthetic valve infection and inconclusive echocardiography findings (29). Of note, PET/CT is not only very sensitive in identifying valvular prosthesis infection but also provides a whole-body assessment for identification of other infectious foci (Fig. 3A). Its diagnostic accuracy is supported by evidence forthcoming from systematic reviews (30), and recent work highlights the importance of early implementation in the diagnostic workup (31). For inconclusive cases, white blood cell SPECT/CT may be of value as a more specific yet time-consuming technique, and cadmium-zinc-telluride technology may further increase accuracy (32).

PET is also expanding toward imaging infection of other devices, including left ventricular assist devices (33). Here, early diagnosis and exact localization of the site of infection may be crucial, because limited involvement of peripheral components is associated with better outcome than involvement of intracardiac components (Fig. 3B) (34). PET effectively guides treatment, which is mostly based on surgical options such as targeted vacuum therapy, substitution of device components, or complete extraction and replacement (33). Molecule-targeted drug therapy options are currently limited to existing antibiotic agents, as novel antiinfective agents are not a focus of industry (35). The potential of molecular imaging to serially monitor antibacterial therapy in device infections has not yet been explored in depth but may represent another area of future growth.

\section{Infiltrative Cardiomyopathies: Amyloidosis}

Amyloidosis is a not-so-rare systemic disease characterized by the interstitial deposition of insoluble protein fibrils that affect tissue structure and function. Cardiac involvement may occur in light-chain amyloidosis and in transthyretin-associated amyloidosis (ATTR, either hereditary or acquired) and limits patient prognosis (36). It is established that bone-seeking radiopharmaceuticals identify cardiac involvement in amyloidosis (36). This approach has seen a recent revival driven by 2 major factors: the first is the increasing evidence that cardiac amyloidosis is more prevalent than previously expected, contributing to significant cases of heart failure with preserved ejection fraction (37), and the second is the clinical introduction of novel targeted molecular therapies for amyloidosis - therapies that may be seen as the major contributing factor for the increased use of bone scans. The transthyretin stabilizer tafamidis was approved for cardiac ATTR after the ATTR-ACT trial showed beneficial effects on survival, hospitalization rate, and quality of life (38). In hereditary ATTR, the RNA silencers inotersen and patisiran are additional targeted therapy options that may improve clinical course $(39,40)$, and antiserum amyloid protein antibodies may be another promising treatment for various types of amyloidosis (41).

In a recent multisociety consensus document, the usefulness of bone-seeking radiotracers in diagnosing cardiac ATTR was highlighted (42), emphasizing early diagnosis of cardiac involvement in transthyretin gene carriers or subjects with proven 


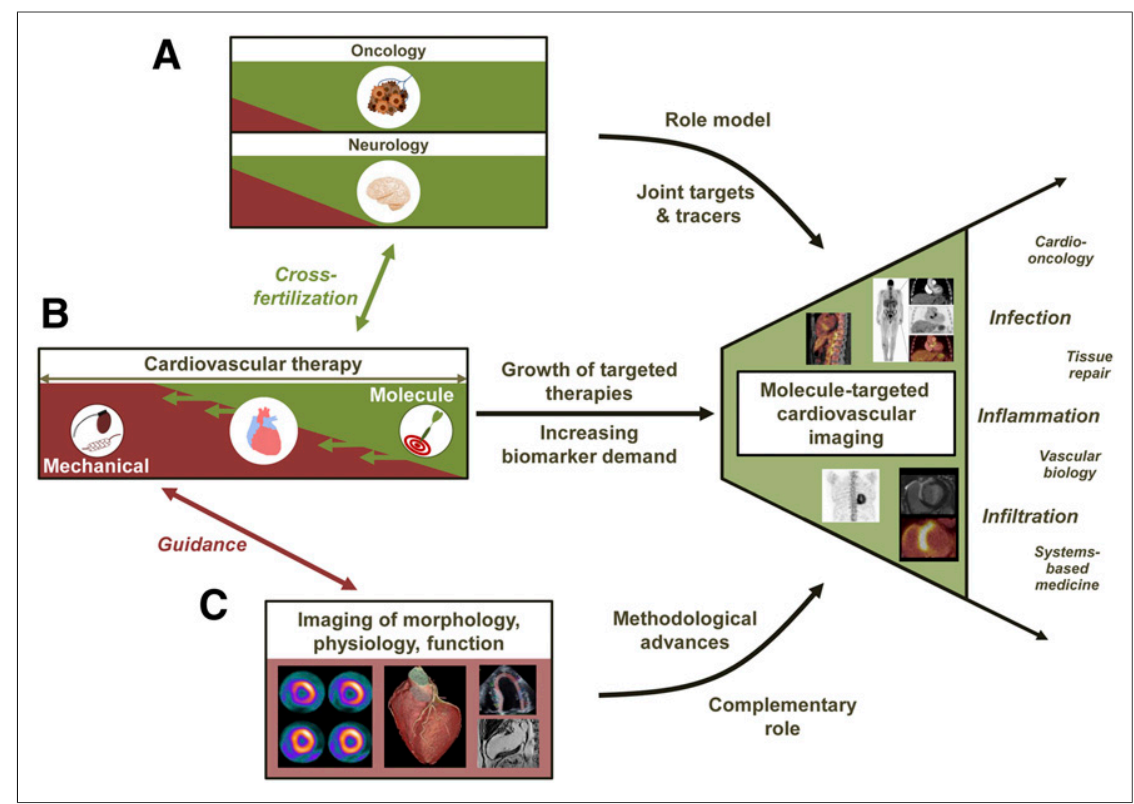

FIGURE 2. Growing role of molecule-targeted cardiovascular imaging, as supported by success of molecular medicine in other areas such as oncology and neurology, serving as role model and providing innovative targets and tracers (A); increasing role of molecule-targeted therapies in cardiology, leading to increasing demand for biomarkers (B); and strong role and further evolution of conventional noninvasive imaging of morphology, physiology, and function, providing high-end methodology and correlative imaging information (C).

systemic ATTR and new onset of cardiac symptoms. The largest role, however, is in the workup of subjects with newly diagnosed heart failure, for which echocardiography or cardiac MRI show findings suggestive of cardiac amyloidosis. In this setting, a bone scan in the absence of monoclonal gammopathy (which would suggest light-chain amyloidosis) either rules out cardiac amyloidosis if negative or is highly specific for cardiac ATTR in cases of moderate or strong cardiac uptake. Endomyocardial biopsies may be avoided, and therapy decisions can be based on the bone scan, fulfilling the concept of the virtual biopsy (43).

Additionally, PET techniques are emerging in amyloidosis. Although the role of the bone-seeking agent ${ }^{18} \mathrm{~F}$-sodium fluoride for the workup of transthyretin cardiac amyloidosis is still under debate because of low signal intensity (44), PET amyloid markers originally developed for neurology to identify $\beta$-amyloid in neurodegenerative disease also detect cardiac amyloidosis. The original ${ }^{11} \mathrm{C}$-labeled Pittsburgh compound B, as well as the ${ }^{18} \mathrm{~F}$-labeled alternatives florbetaben or florbetapir, bind to both ATTR and light-chain amyloidosis in the heart, where they allow quantification of cardiac amyloid burden (45). Importantly, amyloid-targeted PET also provides quantitative information about whole-body amyloid distribution (46). A potential area of growth for amyloid PET is in monitoring treatment efficacy in light-chain amyloidosis and ATTR, similar to early response-monitoring approaches in molecular oncology. Ultimately, the available and increasingly used bone-seeking and amyloid-binding molecular imaging agents establish molecular phenotypes of patients (Fig. 4), which will help in early identification of cardiac amyloidosis, guiding patients toward early and effective molecular treatments (43).

\section{Infiltrative or Inflammatory Cardiomyopathies: Sarcoidosis}

Sarcoidosis is a systemic granulomatous disease wherein cardiac involvement may occur and contribute to adverse outcome. Like amyloidosis, cardiac sarcoidosis is traditionally underdiagnosed, and this underdiagnosis has been a trigger for increasing implementation of novel, reliable imaging tools. Presently, a combination of ${ }^{18}$ F-FDG PET (for the assessment of inflammatory disease extent) and resting myocardial perfusion imaging is recommended by expert consensus, wherein thorough dietary preparation is required to suppress myocardial glucose utilization (47). Under the premise of ${ }^{18}$ F-FDG avidity in granulomatous inflammatory cells, focal or multifocal sites with increased glycolytic activity are indicators of cardiac involvement, particularly with perfusion-metabolism mismatch patterns in which reduced perfusion identifies tissue damage. Nonetheless, focally increased ${ }^{18}$ F-FDG uptake may not necessarily be specific for sarcoid and has been reported in other inflammatory processes, such as Chagas disease (48). Late-gadoliniumenhancement cardiac MRI studies also accurately identify cardiac sarcoid (49). Yet, caution must be exercised in patients with impaired renal function or implantable devices. Also, PET as a whole-body technique readily identifies extracardiac disease sites (Fig. 5). Most importantly, ${ }^{18}$ F-FDG PET has the major advantage of specifically identifying inflammatory activity, which predicts outcome and facilitates assessment of therapy response (49). Currently, ${ }^{18} \mathrm{~F}-\mathrm{FDG}$ PET is considered useful for patients with biopsy-proven extracardiac sarcoid when screening tests (e.g., echocardiography, Holter monitoring, or cardiac MRI) suggest cardiac involvement, unexplained new-onset conduction abnormalities (second- or thirddegree atrioventricular block), or idiopathic sustained ventricular tachycardia and when therapy monitoring is needed for proven cases of cardiac sarcoid (47).

Such therapeutic monitoring is of particular potential, because molecular therapeutic options are increasing. Although not limiting the incidence of potentially lethal arrhythmias but, rather, protecting functional myocardium from scar tissue formation (50), corticosteroids remain the first-line therapy in sarcoidosis. Steroid-sparing agents such as antimetabolites (methotrexate, azathioprine, leflunomide) are also embedded in the therapeutic algorithm. In refractory disease, the therapeutic armamentarium has been further expanded by several drugs targeting T-cell activation, Th1/Th17 pathways, or the ubiquitin-proteasome system (51). Thus, as shown for steroids (52), molecular imaging holds promise to address the clinical need to predict and monitor response. It is likely that only patients with active inflammation will respond to antiinflammatory therapies, unlike those with inactive fibrosis or tissue damage. By extension, response to antiinflammatory therapy is best identified by declining inflammatory activity, and when such a response is not detected, an early change in treatment strategy may be pursued (49).

\section{Inflammation of the Vessel Wall}

Awareness is growing that inflammatory cascades are key drivers for the onset and progression of atherosclerotic plaques, leading to a higher likelihood of plaque rupture (53). This notion 


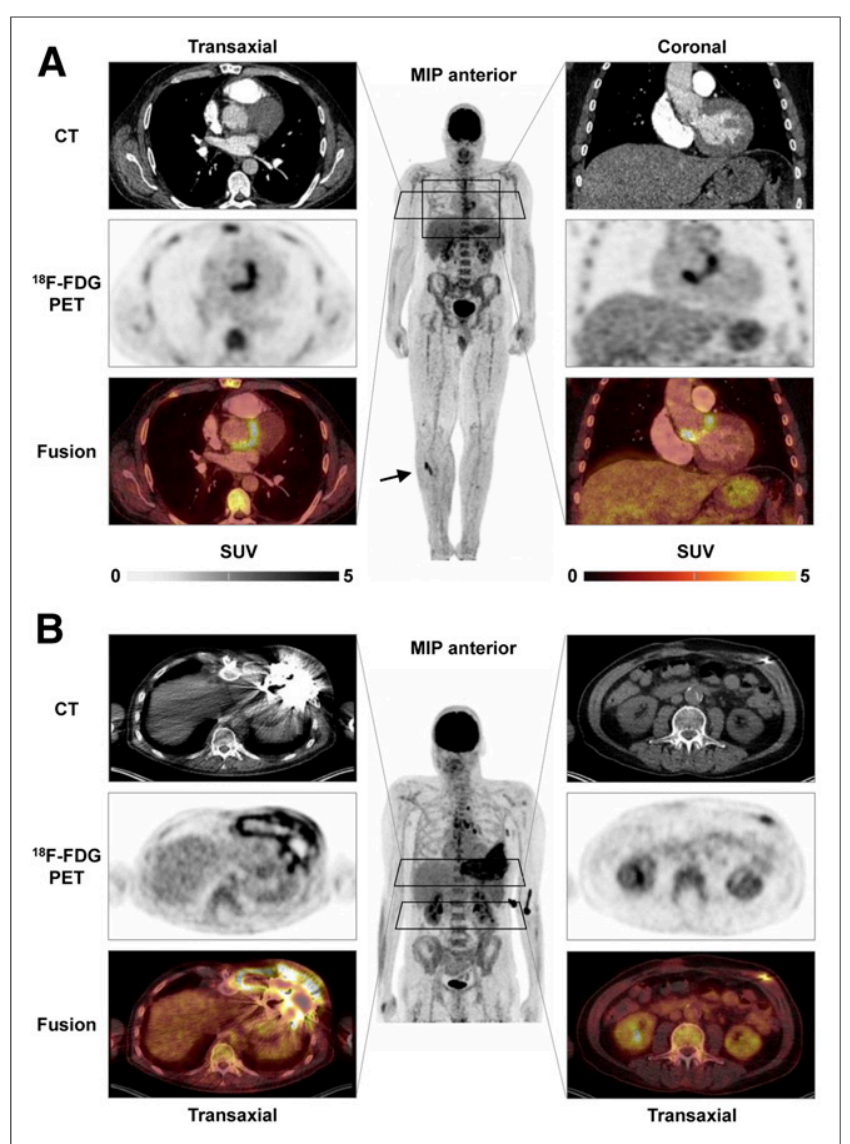

FIGURE 3. ${ }^{18} \mathrm{~F}-\mathrm{FDG}$ PET/CT of cardiovascular device infection. (A) Prosthetic valve endocarditis: CT, PET, and PET/CT fusion images in representative transaxial and coronal views, along with whole-body maximum-intensity projection (MIP). Intense uptake is present at aortic valve prosthesis, implanted 2 y previously. MIP shows additional focal ${ }^{18} \mathrm{~F}-\mathrm{FDG}$-avid embolus in right lower leg (arrow). (B) Left-ventricular assist device infection. Intense uptake is seen around device and outflow tract in left chest wall (left) and along driveline (right) in patient with diffuse reddening and swelling of left chest wall and purulent drainage at entry side of driveline. MIP shows additional uptake in reactive mediastinal lymph nodes.

led to large multicenter trials of antiinflammatory agents. In CANTOS (54), canakinumab, a potent inhibitor of interleukin-1 $\beta$, reduced the rate of recurrent vascular events in patients with stable coronary artery disease who remain at high proinflammatory risk. In CIRT (55), on the other hand, no benefit from low-dose methotrexate was found in post-myocardial infarction subjects with either diabetes or metabolic syndrome. The discrepant results of these trials emphasize the complexity of inflammation in atherosclerosis. They also indirectly point toward the need for a more precise phenotyping of subjects to select candidates who are most likely to respond. Here, molecular imaging of vessel wall inflammation may have significant potential (56).

After initial work using ${ }^{18} \mathrm{~F}-\mathrm{FDG}$ (57), various novel radiopharmaceuticals have been explored to visualize plaque biology, including clinically applied agents such as ${ }^{18} \mathrm{~F}$-sodium fluoride as a marker of microcalcification $(58),{ }^{68} \mathrm{Ga}$-DOTATATE as a marker of macrophage somatostatin receptor expression, and ${ }^{68} \mathrm{Ga}$-pentixafor as a marker of leukocyte chemokine receptor CXCR4 expression (59). In parallel, the targeting of small vascular structures, especially the coronary arteries, has led to technical refinements of PET imaging by including respiratory and cardiac motion correction (60). These developments supported imaging in selected clinical atherosclerosis trials (61) and generated novel and intriguing hypotheses, as well as tools for future projects on image-guided therapy. A clinical role for molecule-targeted plaque imaging, however, has not yet been established, emphasizing the need for more research into combinations of molecular imaging and therapy in atherosclerosis.

Besides atherosclerosis, other applications for molecular imaging of the vessel wall have emerged. ${ }^{18}$ F-FDG PET has, for example, entered clinical practice in the diagnosis of largevessel vasculitis, for which multisociety procedural (62) and clinical use recommendations have been recently published (63). The goal is early diagnosis of vessel wall inflammation indicative of Takayasu or giant cell arteritis and guidance of antiinflammatory therapies. Aortic aneurysm and dissection have also emerged as a target for molecular imaging of microcalcification or inflammatory activity, which may predict progression and complications and guide endovascular repair (64). Finally, similar to cardiac devices and implants, infection of vascular prostheses can also be identified sensitively using ${ }^{18} \mathrm{~F}-\mathrm{FDG}$ PET (65). The vessel wall with its multiple pathologies therefore remains a challenging but attractive area for future growth of molecular imaging (Fig. 6).

\section{Inflammation and Myocardial Repair After Ischemic Damage}

Early reperfusion after acute myocardial infarction has led to an improved survival rate, but lower mortality has been accompanied by a rising incidence and prevalence of heart failure (66). Broad blockbuster therapy is used to improve long-term outcome, but this improvement does not change the phenomenon that some patients with acute myocardial infarction completely recover whereas others exhibit progressive contractile dysfunction and left ventricular remodeling. Accordingly, recent efforts have focused on identifying novel therapeutic targets involved in healing and repair after acute myocardial infarction - targets that may be modified to prevent persistent compromise of myocardial function (67). In this regard, postinfarction inflammation has emerged as a key regulator (67), in that an exacerbated inflammatory response to tissue damage may lead to excessive tissue degradation and scar instability, with sustained left ventricular dysfunction (20). Initially, ${ }^{18} \mathrm{~F}$-FDG was advocated to identify the presence of adverse proinflammatory macrophages in subacutely infarcted myocardium (68). Given sufficient metabolic preparation to suppress myocyte ${ }^{18}$ F-FDG uptake, the metabolic rate of glucose utilization in the infarct territory correlates with glucose utilization rates in spleen and bone marrow (69), confirming an interrelation between myocardium and lymphoid tissue activation. Subsequently, the ${ }^{18}$ F-FDG signal in patients early after acute myocardial infarction was confirmed to have a predictive value for later onset of adverse remodeling (70). However, despite thorough preparation for suppression of myocyte uptake, injured but viable myocytes may still show elevated ${ }^{18} \mathrm{~F}$-FDG uptake and thereby compromise the specificity of the signal for inflammatory cells (71). Thus, novel radiotracers with less physiologic accumulation in the myocardium are desirable (20). For example, the translocator protein-ligand ${ }^{18} \mathrm{~F}$-flutriciclamide (GE180) has been investigated in preclinical and clinical settings, confirming utility to obtain further insights into the inflammatory response during wound healing after 


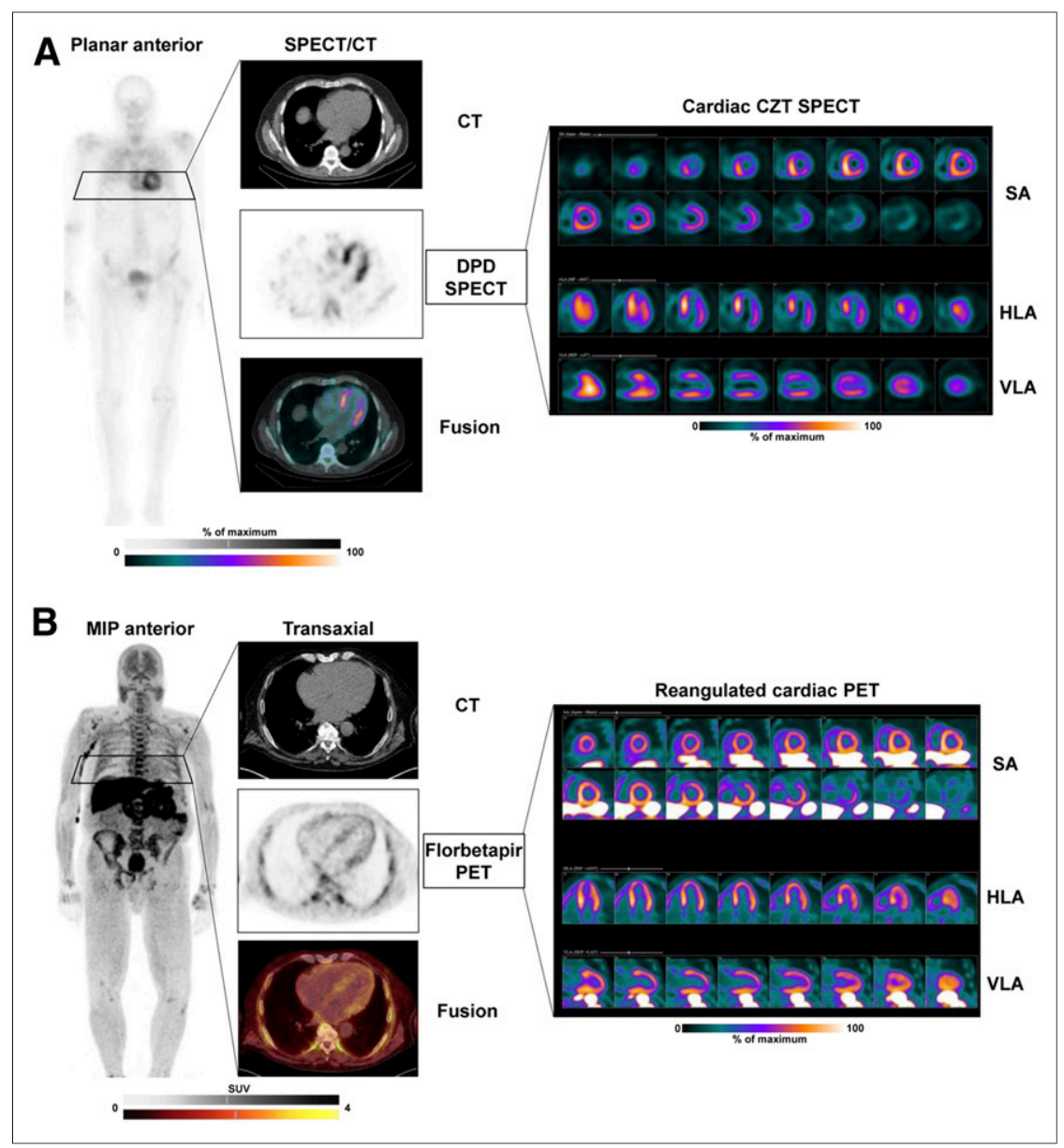

FIGURE 4. Molecular imaging of cardiac amyloidosis. (A) Scintigraphy with bone-seeking tracer ${ }^{99 \mathrm{~m} T c}$-diphosphonopropanodicarboxylic acid (99mTc-DPD) in patient with wild-type ATTR. Shown are planar whole-body image; transaxial CT, SPECT, and SPECT/CT fusion images; and reoriented cardiac images in short-axis (SA), horizontal long-axis (HLA), and vertical long-axis (VLA) views using dedicated cadmium-zinc telluride (CZT) camera. Significant tracer uptake is identified in heart, exceeding bone uptake (Perugini score, 3). Tomographic images show strongest signal in septum. In absence of serum light chains, findings are consistent with cardiac ATTR. (B) PET scan with amyloid marker ${ }^{18} \mathrm{~F}$-florbetapir in patient with light-chain amyloidosis. Whole-body maximum-intensity projection (MIP) shows diffuse bone marrow uptake consistent with involvement of hematopoietic system. Tomographic cardiac images show diffuse myocardial uptake consistent with cardiac light-chain amyloidosis.

acute myocardial infarction (72,73). Ultimately, such moleculetargeted imaging approaches may identify individuals with an adverse immune response who may benefit from targeted immunomodulatory interventions to achieve individually optimized myocardial repair $(74)$.

\section{THE FUTURE: EXPANDING OPPORTUNITIES}

\section{Innovative Radiopharmaceuticals for Clinical Application: Infection, Inflammation, and Fibrosis}

Given the high accumulation of ${ }^{18} \mathrm{~F}-\mathrm{FDG}$ in other nonspecific tissue types throughout the body and the inconvenience of preparing radiolabeled white blood cells, novel targets in molecular imaging of infection and inflammation are emerging. Bacteriaspecific agents such as maltodextrins, which accumulate specifically in the sites of infection without any interactions, are considered a promising new approach for the diagnosis of device-related infection or other bacterial infectious diseases (75). Additionally, a range of novel agents targeting specific components of the immune system is emerging and holds promise for a more precise assessment of beneficial versus adverse effects of the inflammatory response to tissue injury (75). These agents include, but are not limited to, chemokine receptors such as CXCR4, which has been specifically imaged using the ligand ${ }^{68} \mathrm{Ga}$-pentixafor in the myocardium of mice and in patients with acute myocardial infarction (72) and in the atherosclerotic vessel wall (59). Likewise, the ${ }^{68} \mathrm{Ga}$-labeled imaging agent DOTA-ECL1i has been introduced for detecting CCR2-positive monocytes and macrophages (76). And last, various mechanisms downstream of early inflammation, which include a complex interplay of reparative, angiogenic, and fibrotic factors, have emerged as imaging targets, because the extent and relative contribution of these processes in response to myocardial injury is thought to be a determinant of myocardial remodeling. These targets include, for example, $\alpha_{\mathrm{v}} \beta_{3}$ integrin as a transmembrane cell surface receptor that interacts with the extracellular matrix and is upregulated after myocardial infarction (75), or activated fibroblasts detected by the novel ${ }^{68} \mathrm{Ga}$-labeled fibroblast activation protein inhibitors (77). Ultimately, it is hoped that such innovative imaging compounds will be instrumental not only for more precise diagnosis of individual risk of disease progression but also for personalized guidance of novel targeted therapies (Fig. 7).

\section{Image-Guided Drug Development}

Imaging can help in multiple ways to explore, translate, and establish novel targeted therapies in cardiovascular medicine. Although routine morphologic and functional imaging may serve as an endpoint to determine the efficacy of a novel therapy, targeted molecular imaging may be used to characterize the individual disease biology and identify a molecular target that may then be directly manipulated by a specific drug binding via the identical mechanism. This image-guided therapy concept may help in selecting individuals most likely to respond to therapy. Of note, among various novel drugs aiming at modulating the cardiac immune system and fibrosis, specific drugs targeting CXCR4 (78), fibroblast activation protein (77), or other structures amenable for molecular imaging are under evaluation and may be guided by imaging biomarkers. Furthermore, even radionuclide theranostic approaches from nuclear oncology may be translated to cardiovascular medicine. It has, for example, been shown that CXCR4 endoradiotherapy can alter atherosclerotic plaque biology in patients treated for tumors (79), but application in 


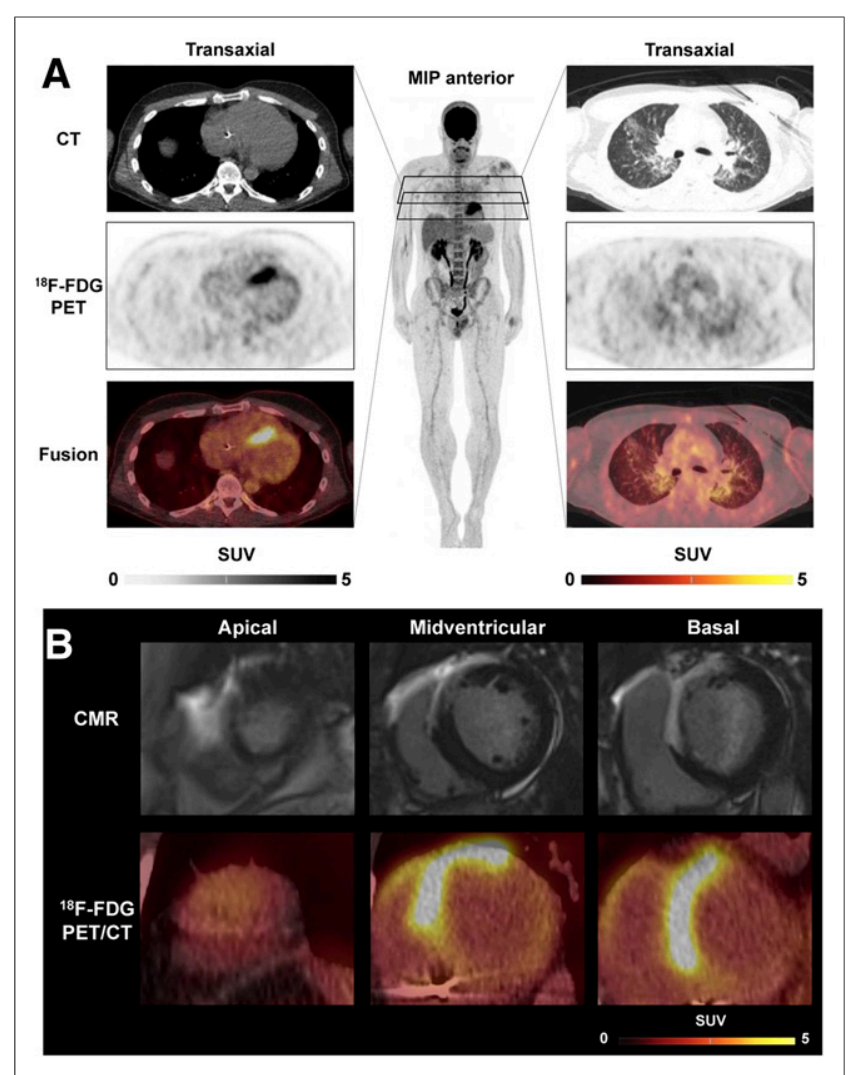

FIGURE 5. ${ }^{18} \mathrm{~F}-\mathrm{FDG}$ PET/CT in cardiac sarcoidosis. (A) Representative transaxial CT, PET, and PET/CT fusion images of cardiac region (left) showing strongly increased septal uptake consistent with biopsy-proven active cardiac sarcoidosis. Images of lung region (right), along with whole-body maximum-intensity projection (MIP), show mild, diffuse uptake in both lung lobes indicating moderately active pulmonary sarcoidosis. (B) Integration with cardiac MRI (CMR), showing transmural late gadolinium enhancement in anterior wall, septum, and anterior portion of right ventricle, colocalizing with ${ }^{18} \mathrm{~F}-\mathrm{FDG}$ uptake in reangulated shortaxis PET/CT images.

primary cardiovascular disease has not yet been pursued. It is highly likely that cardiovascular medicine will see significant growth of such integrated applications of imaging and therapy in the future, opening opportunities for molecular imaging similar to the current success of theranostics in oncology.

\section{Systems-Based Imaging and Therapy: Organ Crosstalk and Cardiooncology}

It is increasingly recognized that organ systems do not operate independently, such that injury to one organ can bear grave consequences for disparate organs. Likewise, any targeted drug may exert beneficial effects in a target region but have adverse effects in remote tissue, potentially limiting its overall benefits. Because radiotracers are applied systemically, organ crosstalk and systems-based analyses of networks are readily pursued by whole-body imaging.

Valuable mechanistic insight into organ-organ interactions have been obtained by image-based interrogation of crosstalk between the damaged heart, the hematopoietic system, and the vessel wall (80). More recently, interaction between the brain and the heart in cardiovascular disease has also been elucidated by confirming amygdalar activity as an independent marker of cardiovascular risk (81) and by confirming the presence of neuroinflammation early after myocardial infarction and in chronic heart failure (73). Likewise, interaction between the failing heart and kidneys, lungs, liver, or even gut and microbiome may emerge as a further target for systems-based medical strategies. Molecular imaging of organ interactions will likely be further fueled by the recent introduction of total-body PET/CT, which enables simultaneous coverage and pharmacokinetic studies of the entire human body (82).

A particular area of systemic interaction is the growing field of cardiooncology. Modern tumor therapies are increasingly effective, leading to better survival of cancer patients but introducing adverse effects to organs not directly affected by oncologic disease. Because established and novel antitumor therapies can affect myocardial integrity, systems-based whole-body in vivo imaging may be used to obtain further insights into the off-target response to cancer therapeutics (83). Radiation-, doxorubicin-, or checkpoint inhibitor-induced cardiotoxicity may be identified by

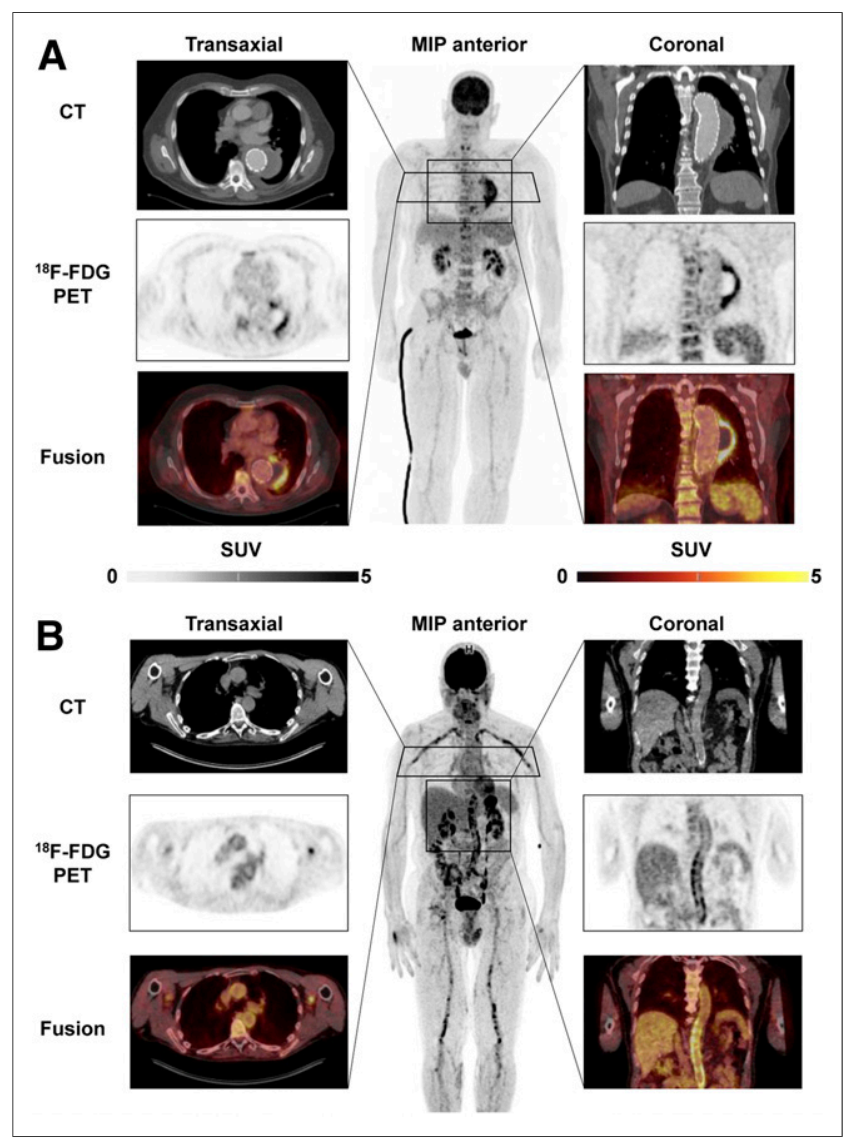

FIGURE 6. ${ }^{18} \mathrm{~F}-\mathrm{FDG}$ PET/CT of vascular inflammation. (A) Vascular graft infection. CT, PET, and PET/CT fusion images in representative transaxial and coronal views, along with whole-body maximumintensity projection (MIP), 12 mo after endovascular aortic repair for aneurysm of descending thoracic aorta. CT is consistent with endoleak of prosthesis, leading to expanding aneurysm, and PET shows intense uptake in periphery of aneurysm, consistent with infection, requiring surgical revision. (B) Large-vessel vasculitis. Shown are representative images in patient with weight loss, elevated level of serum C-reactive protein, and fever of unknown origin. Intense, diffuse elevated uptake in walls of aorta, large arteries of neck, and upper and lower extremities (significantly above liver uptake) is consistent with active giant-cell arteritis. 


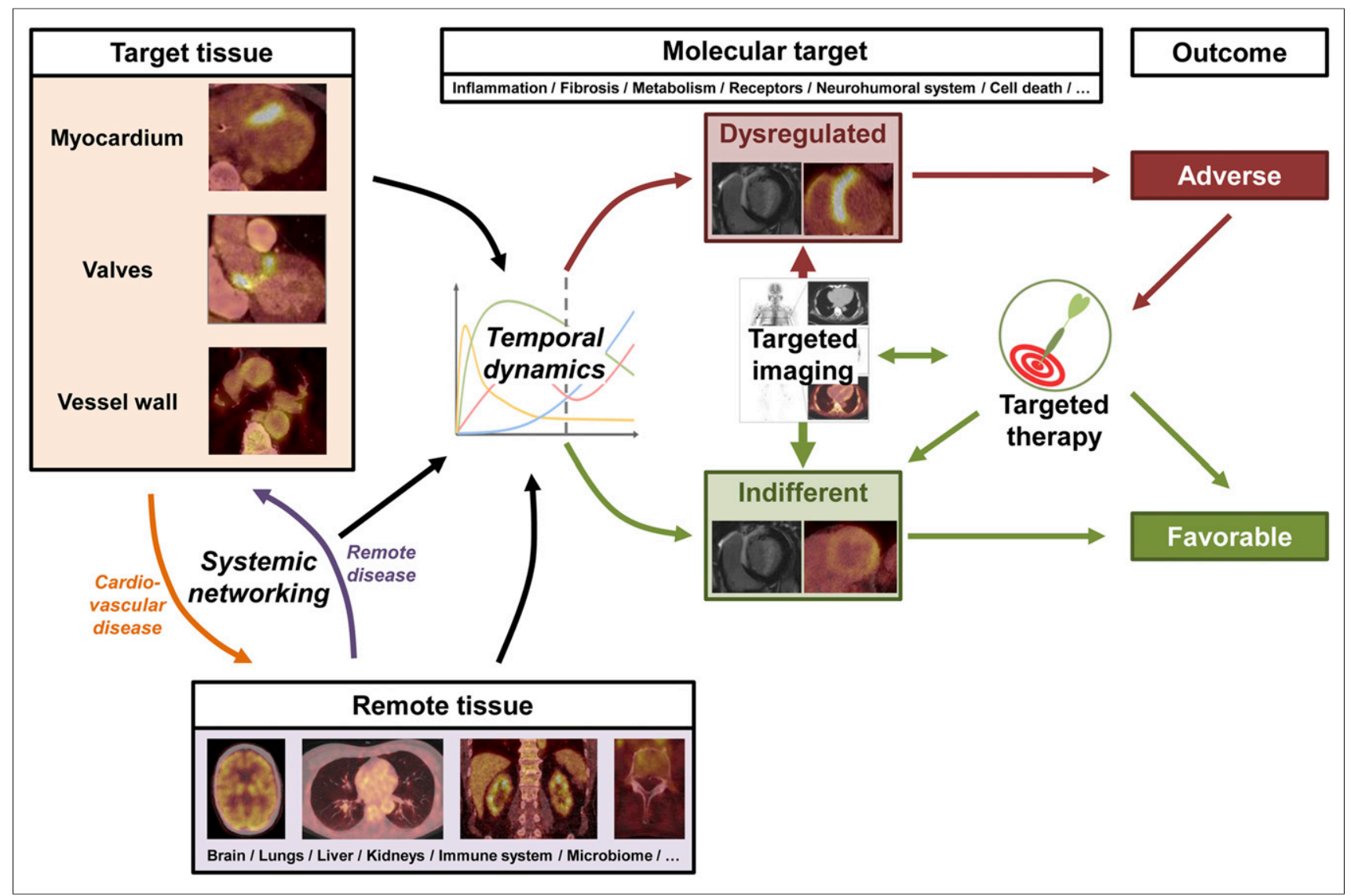

FIGURE 7. Key principle of systems-based, image-guided (molecular) therapy in cardiovascular medicine. Cardiovascular target tissue interacts with remote tissue through various molecular mechanisms, which underlie temporal dynamics and can be targeted by molecular imaging agents. Imaging may identify dysregulation of target mechanism, which indicates risk for adverse outcome. This information may trigger targeted therapy to adjust target mechanism, improve disease course, and achieve favorable outcome.

molecular imaging (83), and assessment of such adverse effects on the cardiovascular system may also offer novel insights into the biology of the myocardium. Thus, given the increasing number of cancer survivors, molecular imaging in cardiooncology is expected to continue to grow.

\section{CONCLUSION}

Radionuclide imaging of myocardial perfusion, function, and viability has always been a centerpiece of clinical practice in nuclear cardiology and serves as a reliable tool for therapeutic guidance in ischemic heart disease. However, alternative techniques such as CT or cardiac MRI have applied evolutionary pressure such that nuclear cardiology has evolved from assessing physiologic function and perfusion toward an interrogation of biology and molecular pathways. Today, molecular imaging of the heart is increasingly requested by cardiologists for infection, inflammation, and infiltration in the cardiovascular system. This trend is further fueled by the advent of an increasing spectrum of novel molecule-targeted drug interventions in cardiology, which require early identification of the most suitable patients and subsequent monitoring of success. As such, given the transformative contribution to the evolution of cardiovascular therapy beyond mechanical interventions toward novel, individualized molecule- targeted therapies, the field of molecular cardiac imaging holds strong potential for a future role in precision cardiology.

\section{DISCLOSURE}

This work was funded by the German Research Foundation (DFG), through the PRACTIS-Clinician Scientist Program of Hannover Medical School (ME 3696/3-1, Rudolf Werner) and the clinical research group KFO311 (Johann Bauersachs and Frank M. Bengel). No other potential conflict of interest relevant to this article was reported.

\section{REFERENCES}

1. Zaret BL, Strauss HW, Martin ND, Wells HP Jr, Flamm MD Jr. Noninvasive regional myocardial perfusion with radioactive potassium: study of patients at rest, with exercise and during angina pectoris. N Engl J Med. 1973;288:809812.

2. Knuuti J, Wijns W, Saraste A, et al. 2019 ESC guidelines for the diagnosis and management of chronic coronary syndromes. Eur Heart J. 2020;41:407-477.

3. De Bruyne B, Pijls NH, Kalesan B, et al. Fractional flow reserve-guided PCI versus medical therapy in stable coronary disease. N Engl J Med. 2012;367:9911001.

4. Greenwood JP, Ripley DP, Berry C, et al. Effect of care guided by cardiovascular magnetic resonance, myocardial perfusion scintigraphy, or NICE guidelines on subsequent unnecessary angiography rates: the CE-MARC 2 randomized clinical trial. JAMA. 2016;316:1051-1060. 
5. Nagel E, Greenwood JP, McCann GP, et al. Magnetic resonance perfusion or fractional flow reserve in coronary disease. N Engl J Med. 2019;380:2418-2428.

6. SCOT-HEART Investigators. Newby DE, Adamson PD, et al. Coronary CT angiography and 5-year risk of myocardial infarction. $N$ Engl J Med. 2018;379: 924-933.

7. Douglas PS, Hoffmann U, Patel MR, et al. Outcomes of anatomical versus functional testing for coronary artery disease. N Engl J Med. 2015;372:12911300 .

8. Bengel FM. Issue "noninvasive molecular imaging and theranostic probes": new concepts in myocardial imaging. Methods. 2017;130:72-78.

9. Werner RA, Bundschuh RA, Bundschuh L, et al. Novel structured reporting systems for theranostic radiotracers. J Nucl Med. 2019;60:577-584.

10. Gould KL, Johnson NP, Bateman TM, et al. Anatomic versus physiologic assessment of coronary artery disease: role of coronary flow reserve, fractional flow reserve, and positron emission tomography imaging in revascularization decision-making. J Am Coll Cardiol. 2013;62:1639-1653.

11. Werner RA, Chen X, Rowe SP, Lapa C, Javadi MS, Higuchi T. Moving into the next era of PET myocardial perfusion imaging: introduction of novel ${ }^{18} \mathrm{~F}$-labeled tracers. Int J Cardiovasc Imaging. 2019;35:569-577.

12. Javadi MS, Lautamaki R, Merrill J, et al. Definition of vascular territories on myocardial perfusion images by integration with true coronary anatomy: a hybrid PET/CT analysis. J Nucl Med. 2010;51:198-203.

13. Rischpler C, Nekolla SG, Dregely I, Schwaiger M. Hybrid PET/MR imaging of the heart: potential, initial experiences, and future prospects. J Nucl Med. 2013;54: $402-415$.

14. Zhang J, Maniawski P, Knopp MV. Performance evaluation of the next generation solid-state digital photon counting PET/CT system. EJNMMI Res. 2018;8:97.

15. Bengel FM. Leaving relativity behind: quantitative clinical perfusion imaging. $J$ Am Coll Cardiol. 2011;58:749-751.

16. Slomka PJ, Miller RJH, Hu LH, Germano G, Berman DS. Solid-state detector SPECT myocardial perfusion imaging. J Nucl Med. 2019;60:1194-1204.

17. Knuuti J, Wijns W, Saraste A, et al. 2019 ESC guidelines for the diagnosis and management of chronic coronary syndromes. Eur Heart J. 2020;41:407-477.

18. Beanlands RS, Nichol G, Huszti E, et al. F-18-fluorodeoxyglucose positron emission tomography imaging-assisted management of patients with severe left ventricular dysfunction and suspected coronary disease: a randomized, controlled trial (PARR-2). J Am Coll Cardiol. 2007;50:2002-2012.

19. Nahrendorf M, Sosnovik DE, French BA, et al. Multimodality cardiovascular molecular imaging, part II. Circ Cardiovasc Imaging. 2009;2:56-70.

20. Thackeray JT, Bengel FM. Gauging cardiac repair and regeneration with new molecular probes. J Nucl Med. 2018;59:549-550.

21. Muñoz D, Uzoije P, Reynolds C, et al. Polypill for cardiovascular disease prevention in an underserved population. $N$ Engl J Med. 2019;381:1114-1123.

22. Femia FJ, Maresca KP, Hillier SM, et al. Synthesis and evaluation of a series of ${ }^{99 \mathrm{~m}} \mathrm{Tc}(\mathrm{CO})_{3}{ }^{+}$lisinopril complexes for in vivo imaging of angiotensin-converting enzyme expression. J Nucl Med. 2008;49:970-977.

23. Merlet P, Delforge J, Syrota A, et al. Positron emission tomography with ${ }^{11} \mathrm{C}$ CGP-12177 to assess beta-adrenergic receptor concentration in idiopathic dilated cardiomyopathy. Circulation. 1993;87:1169-1178.

24. Gheorghiade M, Larson CJ, Shah SJ, et al. Developing new treatments for heart failure: focus on the heart. Circ Heart Fail. 2016;9:e002727.

25. Heitzer E, Perakis S, Geigl JB, Speicher MR. The potential of liquid biopsies for the early detection of cancer. NPJ Precis Oncol. 2017;1:36.

26. Werner RA, Schmid JS, Higuchi T, et al. Predictive value of ${ }^{18} \mathrm{~F}$-FDG PET in patients with advanced medullary thyroid carcinoma treated with vandetanib. J Nucl Med. 2018;59:756-761.

27. Ma Y, Tang C, Chaly T, et al. Dopamine cell implantation in Parkinson's disease: long-term clinical and ${ }^{18}$ F-FDOPA PET outcomes. J Nucl Med. 2010;51:7-15.

28. Long JM, Holtzman DM. Alzheimer disease: an update on pathobiology and treatment strategies. Cell. 2019;179:312-339.

29. Habib G, Lancellotti P, Antunes MJ, et al. 2015 ESC guidelines for the management of infective endocarditis: the task force for the management of infective endocarditis of the European Society of Cardiology (ESC). Endorsed by: European Association for Cardio-Thoracic Surgery (EACTS), the European Association of Nuclear Medicine (EANM). Eur Heart J. 2015;36:30753128 .

30. Gomes A, Glaudemans A, Touw DJ, et al. Diagnostic value of imaging in infective endocarditis: a systematic review. Lancet Infect Dis. 2017;17:e1-e14

31. Swart LE, Gomes A, Scholtens AM, et al. Improving the diagnostic performance of ${ }^{18} \mathrm{~F}$-fluorodeoxyglucose positron-emission tomography/computed tomography in prosthetic heart valve endocarditis. Circulation. 2018;138:1412-1427.

32. Caobelli F, Wollenweber T, Bavendiek U, et al. Simultaneous dual-isotope solidstate detector SPECT for improved tracking of white blood cells in suspected endocarditis. Eur Heart J. 2017;38:436-443.
33. Sommerlath Sohns J, Kroehn H, Schoede A, et al. ${ }^{18}$ F-fluorodeoxyglucose positron emission tomography/computed tomography in left-ventricular assist device infection: initial results supporting the usefulness of image-guided therapy. J Nucl Med. December 5, 2019 [Epub ahead of print].

34. Kim J, Feller ED, Chen W, Liang Y, Dilsizian V. FDG PET/CT for early detection and localization of left ventricular assist device infection: impact on patient management and outcome. JACC Cardiovasc Imaging. 2019;12:722-729.

35. Theuretzbacher U, Gottwalt S, Beyer P, et al. Analysis of the clinical antibacterial and antituberculosis pipeline. Lancet Infect Dis. 2019;19:e40-e50.

36. Ruberg FL, Grogan M, Hanna M, Kelly JW, Maurer MS. Transthyretin amyloid cardiomyopathy: JACC state-of-the-art review. J Am Coll Cardiol. 2019;73: 2872-2891.

37. Gilstrap LG, Dominici F, Wang Y, et al. Epidemiology of cardiac amyloidosisassociated heart failure hospitalizations among fee-for-service Medicare beneficiaries in the United States. Circ Heart Fail. 2019;12:e05407.

38. Maurer MS, Schwartz JH, Gundapaneni B, et al. Tafamidis treatment for patients with transthyretin amyloid cardiomyopathy. N Engl J Med. 2018;379:1007-1016.

39. Adams D, Gonzalez-Duarte A, O'Riordan WD, et al. Patisiran, an RNAi therapeutic, for hereditary transthyretin amyloidosis. N Engl J Med. 2018;379:11-21.

40. Benson MD, Waddington-Cruz M, Berk JL, et al. Inotersen treatment for patients with hereditary transthyretin amyloidosis. N Engl J Med. 2018;379:22-31.

41. Richards DB, Cookson LM, Berges AC, et al. Therapeutic clearance of amyloid by antibodies to serum amyloid P component. $N$ Engl J Med. 2015;373:1106-1114.

42. Dorbala S, Ando Y, Bokhari S, et al. ASNC/AHA/ASE/EANM/HFSA/ISA/ SCMR/SNMMI expert consensus recommendations for multimodality imaging in cardiac amyloidosis: part 1 of 2-evidence base and standardized methods of imaging. J Card Fail. 2019;25:e1-e39.

43. Bullock-Palmer RP. Diagnosing cardiac amyloidosis: a wealth of new possibilities with nuclear cardiac imaging. J Nucl Cardiol. May 13, 2019 [Epub ahead of print].

44. Martineau P, Finnerty V, Giraldeau G, Authier S, Harel F, Pelletier-Galarneau M. Examining the sensitivity of ${ }^{18} \mathrm{~F}-\mathrm{NaF}$ PET for the imaging of cardiac amyloidosis. J Nucl Cardiol. March 4, 2019 [Epub ahead of print].

45. Bravo PE, Dorbala S. Targeted nuclear imaging probes for cardiac amyloidosis. Curr Cardiol Rep. 2017;19:59.

46. Ehman EC, El-Sady MS, Kijewski MF, et al. Early detection of multiorgan lightchain amyloidosis by whole-body ${ }^{18} \mathrm{~F}$-florbetapir PET/CT. J Nucl Med. 2019;60: 1234-1239.

47. Chareonthaitawee P, Beanlands RS, Chen W, et al. Joint SNMMI-ASNC expert consensus document on the role of ${ }^{18} \mathrm{~F}-\mathrm{FDG} \mathrm{PET} / \mathrm{CT}$ in cardiac sarcoid detection and therapy monitoring. J Nucl Med. 2017;58:1341-1353.

48. Salimy MS, Parwani PJ, Mukai K, Pampaloni MH, Flavell RR. Abnormal ${ }^{18} \mathrm{~F}$ FDG and ${ }^{82} \mathrm{Rb}$ PET findings in Chagas heart disease. Clin Nucl Med. 2017;42: e265-e268.

49. Bravo PE, Singh A, Di Carli MF, Blankstein R. Advanced cardiovascular imaging for the evaluation of cardiac sarcoidosis. J Nucl Cardiol. 2019;26:188-199.

50. Fussner LA, Karlstedt E, Hodge DO, et al. Management and outcomes of cardiac sarcoidosis: a 20-year experience in two tertiary care centres. Eur J Heart Fail. 2018;20:1713-1720.

51. Chiarchiaro J, Chen BB, Gibson KF. New molecular targets for the treatment of sarcoidosis. Curr Opin Pulm Med. 2016;22:515-521.

52. Orii M, Hirata K, Tanimoto $\mathrm{T}$, et al. Comparison of cardiac MRI and ${ }^{18} \mathrm{~F}-\mathrm{FDG}$ positron emission tomography manifestations and regional response to corticosteroid therapy in newly diagnosed cardiac sarcoidosis with complete heart block. Heart Rhythm. 2015;12:2477-2485.

53. Harrington RA. Targeting inflammation in coronary artery disease. $N$ Engl $J$ Med. 2017;377:1197-1198.

54. Ridker PM, Everett BM, Thuren T, et al. Antiinflammatory therapy with canakinumab for atherosclerotic disease. N Engl J Med. 2017;377:1119-1131.

55. Ridker PM, Everett BM, Pradhan A, et al. Low-dose methotrexate for the prevention of atherosclerotic events. N Engl J Med. 2019;380:752-762.

56. Derlin T, Bengel FM. Canakinumab for atherosclerotic disease. $N$ Engl J Med. 2018;378:196-197.

57. Rudd JH, Warburton EA, Fryer TD, et al. Imaging atherosclerotic plaque inflammation with $\left[{ }^{18} \mathrm{~F}\right]$-fluorodeoxyglucose positron emission tomography. Circulation. 2002;105:2708-2711.

58. Joshi NV, Vesey AT, Williams MC, et al. ${ }^{18} \mathrm{~F}$-fluoride positron emission tomography for identification of ruptured and high-risk coronary atherosclerotic plaques: a prospective clinical trial. Lancet. 2014;383:705-713.

59. Weiberg D, Thackeray JT, Daum G, et al. Clinical molecular imaging of chemokine receptor CXCR4 expression in atherosclerotic plaque using ${ }^{68} \mathrm{Ga}$-pentixafor PET: correlation with cardiovascular risk factors and calcified plaque burden. J Nucl Med. 2018;59:266-272. 
60. Rubeaux M, Joshi NV, Dweck MR, et al. Motion correction of ${ }^{18} \mathrm{~F}-\mathrm{NaF}$ PET for imaging coronary atherosclerotic plaques. J Nucl Med. 2016;57:54-59.

61. Fayad ZA, Mani V, Woodward M, et al. Safety and efficacy of dalcetrapib on atherosclerotic disease using novel non-invasive multimodality imaging (dalPLAQUE): a randomised clinical trial. Lancet. 2011;378:1547-1559.

62. Slart RH; Writing Group; Reviewer Group; Members of EANM Cardiovascular; Members of EANM Infection \& Inflammation; Members of Committees, SNMMI Cardiovascular; Members of Council, PET Interest Group; Members of ASNC; EANM Committee Coordinator. FDG-PET/CT(A) imaging in large vessel vasculitis and polymyalgia rheumatica: joint procedural recommendation of the EANM, SNMMI, and the PET Interest Group (PIG), and endorsed by the ASNC. Eur J Nucl Med Mol Imaging. 2018;45:1250-1269.

63. Dejaco C, Ramiro S, Duftner C, et al. EULAR recommendations for the use of imaging in large vessel vasculitis in clinical practice. Ann Rheum Dis. 2018;77: 636-643.

64. Forsythe RO, Dweck MR, McBride OMB, et al. ${ }^{18} \mathrm{~F}$-sodium fluoride uptake in abdominal aortic aneurysms: the SoFIA ${ }^{3}$ study. J Am Coll Cardiol. 2018;71:513-523.

65. Reinders Folmer EI, Von Meijenfeldt GCI, Van der Laan MJ, et al. Diagnostic imaging in vascular graft infection: a systematic review and meta-analysis. Eur J Vasc Endovasc Surg. 2018;56:719-729.

66. Velagaleti RS, Pencina MJ, Murabito JM, et al. Long-term trends in the incidence of heart failure after myocardial infarction. Circulation. 2008;118:2057-2062.

67. Bengel FM. Imaging of post-infarct inflammation: moving forward toward clinical application. Circ Cardiovasc Imaging. 2016;9:e004713.

68. Lee WW, Marinelli B, van der Laan AM, et al. PET/MRI of inflammation in myocardial infarction. J Am Coll Cardiol. 2012;59:153-163.

69. Wollenweber T, Roentgen P, Schafer A, et al. Characterizing the inflammatory tissue response to acute myocardial infarction by clinical multimodality noninvasive imaging. Circ Cardiovasc Imaging. 2014;7:811-818.

70. Rischpler C, Dirschinger RJ, Nekolla SG, et al. Prospective evaluation of ${ }^{18} \mathrm{~F}-$ fluorodeoxyglucose uptake in postischemic myocardium by simultaneous positron emission tomography/magnetic resonance imaging as a prognostic marker of functional outcome. Circ Cardiovasc Imaging. 2016;9:e004316.

71. Glasenapp A, Derlin K, Wang Y, et al. Multimodality imaging of inflammation and ventricular remodeling in pressure-overload heart failure. J Nucl Med. 2020; 61:590-596
72. Thackeray JT, Derlin T, Haghikia A, et al. Molecular imaging of the chemokine receptor CXCR4 after acute myocardial infarction. JACC Cardiovasc Imaging. 2015;8:1417-1426.

73. Thackeray JT, Hupe HC, Wang Y, et al. Myocardial inflammation predicts remodeling and neuroinflammation after myocardial infarction. J Am Coll Cardiol. 2018;71:263-275

74. Hess A, Thackeray JT, Wollert KC, Bengel FM. Radionuclide image-guided repair of the heart. JACC Cardiovasc Imaging. December 18, 2019 [Epub ahead of print].

75. Thackeray JT, Bengel FM. Molecular imaging of myocardial inflammation with positron emission tomography post-ischemia: a determinant of subsequent remodeling or recovery. JACC Cardiovasc Imaging. 2018;11:1340-1355.

76. Heo GS, Kopecky B, Sultan D, et al. Molecular imaging visualizes recruitment of inflammatory monocytes and macrophages to the injured heart. Circ Res. 2019; 124:881-890.

77. Varasteh Z, Mohanta S, Robu S, et al. Molecular imaging of fibroblast activity after myocardial infarction using a ${ }^{68} \mathrm{Ga}$-labelled fibroblast activation protein inhibitor FAPI-04. J Nucl Med. 2019;60:1743-1749.

78. Wang Y, Dembowsky K, Chevalier E, et al. C-X-C motif chemokine receptor 4 blockade promotes tissue repair after myocardial infarction by enhancing regulatory $\mathrm{T}$ cell mobilization and immune-regulatory function. Circulation. 2019; 139:1798-1812.

79. Schatka I, Wollenweber T, Haense C, Brunz F, Gratz KF, Bengel FM. Peptide receptor-targeted radionuclide therapy alters inflammation in atherosclerotic plaques. J Am Coll Cardiol. 2013;62:2344-2345.

80. Nahrendorf M, Frantz S, Swirski FK, et al. Imaging systemic inflammatory networks in ischemic heart disease. J Am Coll Cardiol. 2015;65:1583-1591.

81. Tawakol A, Ishai A, Takx RA, et al. Relation between resting amygdalar activity and cardiovascular events: a longitudinal and cohort study. Lancet. 2017;389: 834-845.

82. Badawi RD, Shi $\mathrm{H}, \mathrm{Hu}$, et al. First human imaging studies with the EXPLORER total-body PET scanner. J Nucl Med. 2019;60:299-303.

83. Dreyfuss AD, Bravo PE, Koumenis C, Ky B. Precision cardio-oncology. J Nucl Med. 2019;60:443-450. 